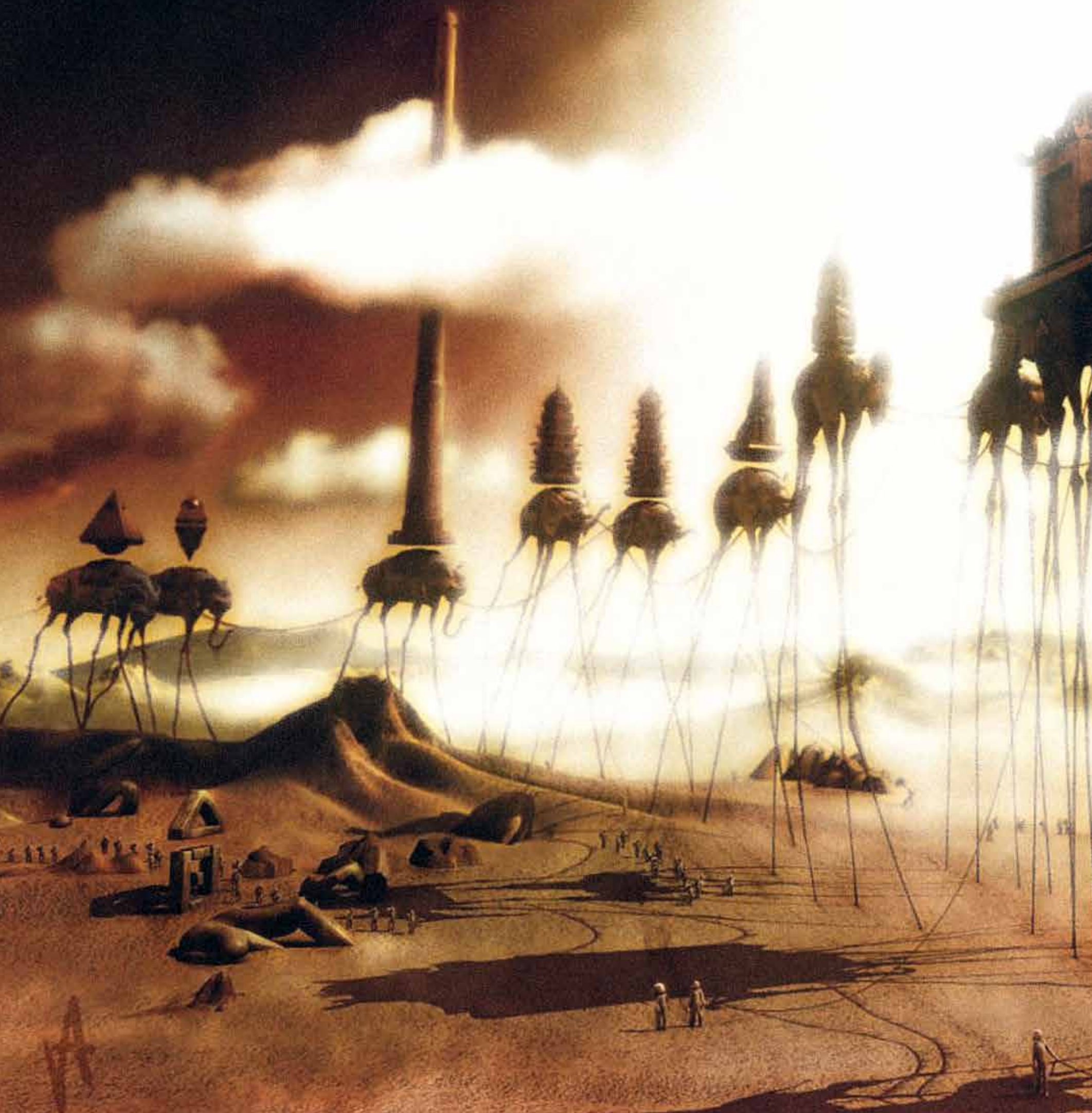




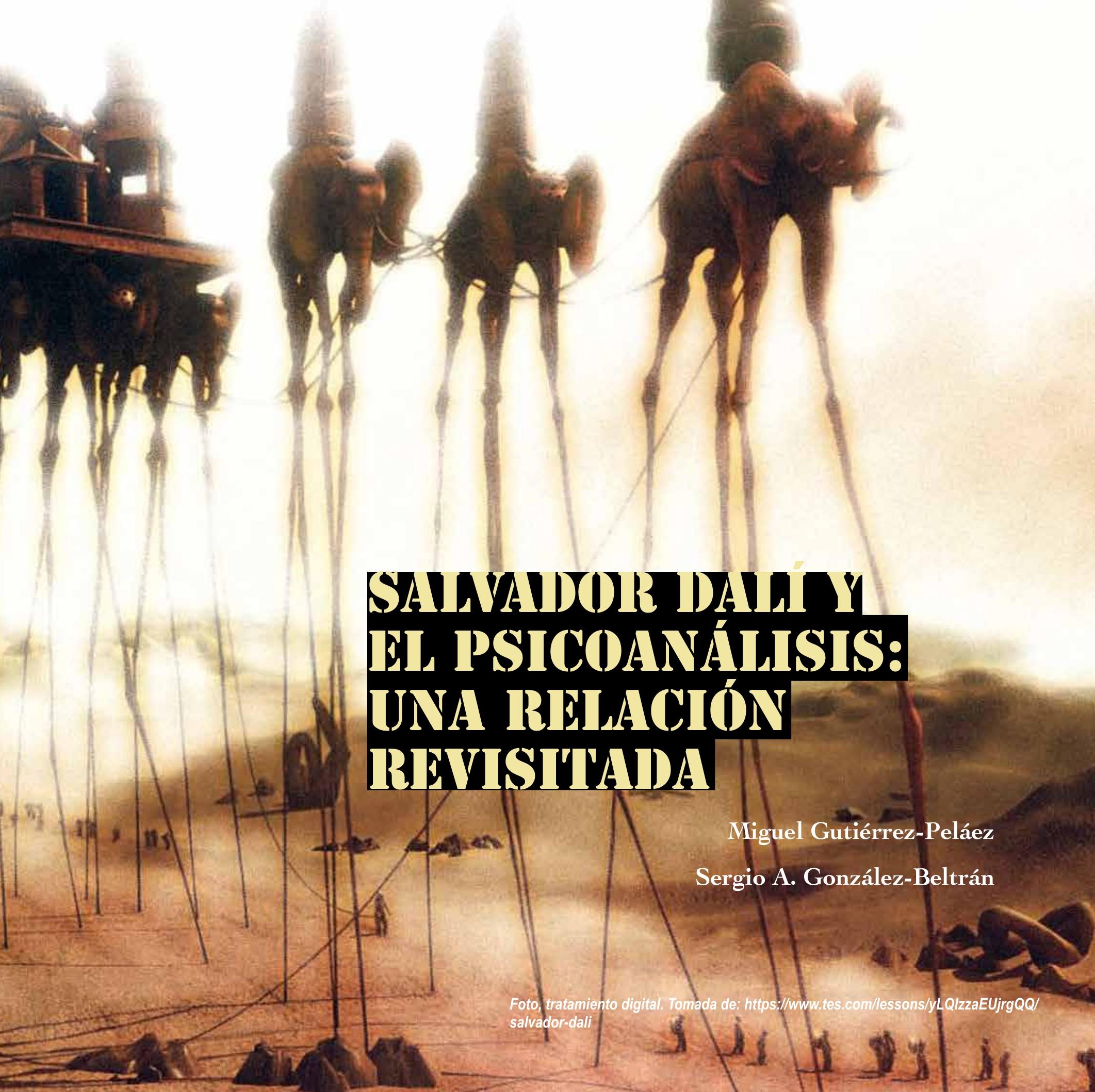




\title{
Salvador Dalí y el psicoanálisis: una relación revisitada
}

\section{Resumen}

La relación entre el surrealismo y el psicoanálisis tiene su fundamento en el hecho de que tanto Salvador Dalí como André Breton se sintieron fuertemente influenciados por las nuevas comprensiones sobre el psiquismo humano, el arte y la creatividad que se abrían con los escritos de Sigmund Freud. A través de una revisión de literatura, se observa la influencia de la obra psicoanalítica en la vida y obra de Salvador Dalí y su relación con el movimiento psicoanalítico. Se revisan los encuentros en persona entre Dalí y Freud por medio de la correspondencia de la época y los efectos que tienen en cada uno de ellos. Se encontró que la relación de Dalí con el psicoanálisis se ubica en el plano teórico y personal. Incluso, en un intento de pensar más allá de Freud, Salvador Dalí teoriza lo que denomina el "método paranoico-crítico", que es una propuesta para poner la paranoia al servicio de la creatividad, idea que fue rescatada por el psicoanalista francés Jacques Lacan.

Palabras clave: Sigmund Freud; Salvador Dalí; surrealismo; psicoanálisis; método paranoico-crítico.

\section{Salvador Dali and Psychoanalysis: A Relationship Revisited}

\begin{abstract}
The relation between Surrealism and Psychoanalysis is based on the fact that both Salvador Dalí and André Breton felt strongly influenced by the new insights on the human psyche, art and creativity gained with the writings of Sigmund Freud. Through a review of literature, the influence of the psychoanalytic work on the life and work of Salvador Dalí is observed, as well as his relationship with the psychoanalytic movement. The face-to-face encounters between both individuals are reviewed through the correspondence of the time, as well as the effects that such encounters had in each of them. It was found that Dalí's relationship with psychoanalysis is both at a theoretical and personal level. Even so, in an attempt to think beyond Freud, Salvador Dalí theorizes what he called the "paranoid-critical method", which is a proposal to put paranoia at the service of creativity, an idea that was revived by French psychoanalyst Jacques Lacan.
\end{abstract}

Keywords: Sigmund Freud; Salvador Dalí; surrealism; psychoanalysis; paranoidcritical method.

\section{Salvador Dalí e a psicanálise: uma relação revistada}

\section{Resumo}

A relação entre surrealismo e psicanálise fundamenta-se no fato de que tanto Salvador Dalí como André Breton sentiram-se fortemente influenciados pelas novas compreensões sobre o psiquismo humano, a arte e a criatividade que surgiam com os textos de Sigmund Freud. Através de uma revisão de literatura, observa-se a influência da obra psicanalítica na vida e obra de Salvador Dalí e sua relação com o movimento psicanalítico. Além disso, foram revisados os encontros em pessoa dos dois personagens por meio da correspondência da época e os efeitos que surgem em cada um deles. Encontrou-se que a relação de Dalí com a psicanálise está situada no plano teórico e pessoal. Mesmo em um intento de pesar além de Freud, Salvador Dalí teoriza aquilo que denomina o "método paranoicocrítico", que é uma proposta para pôr a paranoia ao serviço da criatividade, ideia que foi retomada pelo psicanalista francês Jacques Lacan.

Palavras chave: Sigmund Freud; Salvador Dalí; surrealismo; psicanálise; método paranoico-crítico. 


\section{Introducción}

Salvador Dalí fue uno de los artistas más grandes del siglo xx. Se destacó por su particular uso de imágenes impactantes que no reproducían la realidad, sino que la presentaban transformada y enriquecida con elementos simbólicos y deformaciones que encontraba similares a las del trabajo del sueño. Su obra incorpora también episodios significativos de su vida, lo cual ha despertado el interés de diferentes investigadores, entre ellos varios orientados por el psicoanálisis, quienes han estudiado ampliamente tanto su actividad creativa y su obra, como aspectos de su biografía y personalidad.

Desde sus inicios, el arte y la teoría psicoanalítica han generado una relación estrecha debido al interés de esta corriente de pensamiento por las creaciones humanas, las cuales son vistas como respuestas del hombre ante estímulos internos y externos al aparato psíquico (Loza, 2006). Zuleta (1986) explica que el psicoanálisis le atribuye al arte un potencial de representación significativo y es considerado una dimensión esencial del hombre. Desde la perspectiva freudiana, el arte es la construcción de un mundo sobrecargado por aquellas experiencias ya vividas, en el que el sujeto proyecta sus dramas, temores, esperanzas y deseos.

Varios autores han rastreado las relaciones entre Salvador Dalí y el psicoanálisis, dentro de los que se destacan Guimón (2006), Iribas (2004), Lázaro (2010), Maddox (1990), y Romm y Slap (1983). Estos autores relatan el expreso deseo de Dalí por tener un encuentro con Freud, a quienes los surrealistas, desde André Breton, ubicaban como patrono de su movimiento. Están documentados los múltiples intentos que hace Dalí para encontrarse con Freud y las reiteradas oportunidades en que Freud pospone ese encuentro. En 1922, Dalí fue a Madrid a estudiar Bellas Artes, donde sus compañeros de la residencia estudiantil (Bello, Lorca, Buñuel) lo describían como extremadamente tímido. En un intento por cambiar esta cualidad propia, en 1923, a la edad de 21 años, Dalí comienza a leer ávidamente La interpretación de los sueños de Freud (2004 [1990]), obra que consideraba uno de los "descubrimientos capitales" de su vida, la cual marcó su pensamiento estético e inició su relación idealizada con Freud y el psicoanálisis, pues le permitió hacer sus propias interpretaciones de sus sueños y experiencias personales, al igual que expresar y plasmar en el lienzo sus fantasías diurnas y oníricas (Sánchez y Ramos, 2007).

Dalí frecuentemente se refirió a la influencia de Freud en su obra, afirmando que varias de sus pinturas eran concebidas con base en "principios freudianos" o, por otra parte, dedicando a Freud parte de la producción de su actividad artística. Como muestra de esta admiración, en una oportunidad, en rechazo de una acusación de antisemitismo, Dalí escribió: "las dos personalidades quienes yo más estimo y quienes han influenciado mi vida [...] (son) judíos: Freud y Einstein” (Romm y Slap, 1983, p. 339).

Dalí fue a Viena en tres oportunidades con la intención de reunirse con Freud. Estos intentos infructuosos son narrados por el artista español:

Mis tres viajes a Viena fueron exactamente como tres gotas de agua, faltas de reflejos que las hicieran brillar. En cada uno de estos viajes hice exactamente lo mismo: por la mañana, iba a ver el Vermeer de la colección Czernin, y a la tarde, no iba a visitar a Freud, porque invariablemente me decían que estaba fuera de la ciudad por motivos de salud. (Dalí, 1981, p. 23).

Aunque sus intentos por contactar a Freud no se concretaban, Dalí fantaseaba con la tan anhelada reunión, sumergiéndose en conversaciones imaginarias con él:

Recuerdo con dulce melancolía haber pasado esas tardes vagando al azar por las calles de la antigua capital de Austria. La tarta de chocolate, que comía precipitadamente en los breves intervalos de mis idas de uno a otro anticuario, tenía un sabor levemente amargo, producido por las antigüedades que veía y acentuado por la burla de una entrevista que no ocurría. Al anochecer mantenía largas y cabales conversaciones imaginarias con Freud; hasta me acompañó una vez y permaneció conmigo la noche entera pegado a las cortinas de mi pieza del hotel Sacher. (Dalí, 1981, p. 25).

Dalí realizó cuatro retratos de Freud entre 1937 y 1938. El primero de ellos es un bosquejo realizado con la técnica de tinta china sobre papel, inspirado en la fotografía de un periódico. En este retrato se puede observar un Freud inverosímil, su imagen aparece inanimada, estática, semejándose más a una estatua que a una persona viva. El segundo retrato lo realiza en la segunda semana de junio de 1938:

Varios años después de mi último intento ineficaz por reunirme con Freud, hice una excursión gastronómica por la región de Sens, en Francia. Empezamos la comida con caracoles, uno de mis platos favoritos. La conversación recayó en Edgar Allan Poe, magnífico tema para acompañar el paladeo de los caracoles, y se ocupó especialmente de un libro, recién publicado, de la princesa de Grecia, Marie Bonaparte, que es un estudio psicoanalítico de Poe. De pronto vi una fotografía del profesor Freud en la primera página de un periódico que alguien estaba leyendo junto a mí. Inmediatamente me hice traer un ejemplar y leí que el desterrado Freud acababa de llegar a París. No nos habíamos repuesto del efecto de esta noticia cuando lance un grito. ¡En aquel mismo instante había descubierto el secreto morfológico de Freud! ¡El cráneo de Freud es un caracol! Su cerebro tiene forma de una espiral - ¡que hay que sacar con una aguja! Este descubrimiento influyó mucho en el dibujo de su retrato que hice más adelante del natural, un año antes de su muerte. (p. 26). 

Este segundo retrato de Freud elaborado por Dalí fue inspirado en ese descubrimiento morfológico, mostrando al primero (cuyo rostro lleva una expresión de ira) en diferentes perspectivas, con el cráneo análogo a la concha de un caracol. Romm y Slap (1983) interpretan esta imagen como un sueño, señalando que Dalí leía sobre Freud y disfrutaba de su plato favorito (caracoles) cuando comprendió la imagen: "si el cerebro de Freud era la concha de un caracol, entonces Dalí estaba comiendo el cerebro de Freud" (p. 343). Esta era la parte que Dalí más admiraba de Freud y que él deseaba incorporar. Con respecto a la expresión de ira que lleva el rostro de Freud, los autores interpretan que Dalí está enojado con Freud por sus rechazos previos, y proyecta esta emoción en el rostro del retrato; así mismo, el caracol es despreciado por no haberse asomado de su concha para rendir homenaje a Dalí.

El tan ansiado encuentro se llevó finalmente a cabo el 19 de julio de 1938, en una visita organizada por el escritor austriaco Stefan $Z$ weig, amigo y corresponsal de Freud. Zweig le dijo a él que Dalí era "el único pintor de genio en nuestra época” (Romm y Slap, 1983, p. 344). A dicha reunión asistieron Zweig, Dalí, Gala (Elena Ivanovna Diakonova, mejor conocida como Gala Eluard Dalí, esposa de Salvador Dalí) y el poeta Edward James. Los visitantes habían planeado presentar a Freud el cuadro de Dalí titulado Narciso, cuya visualización consideraban justificaba su visita. De igual manera, los visitantes querían llevar un disco de gramófono, cuyo registro contenía la lectura de un poema de Dalí, el cual se planeaba reproducir mientras se exhibía el cuadro. Esta idea no pudo concretarse debido a que se presentó una dificultad en el transporte de los equipos técnicos.

Dalí relata los momentos previos a su encuentro con Freud con las siguientes palabras:

[...] debía verme con Freud, finalmente, en Londres. Me acompañaban el escritor Stefan Zweig y el poeta Edward James. Mientras cruzaba el patio del anciano profesor vi una bicicleta apoyada en la pared y sobre la silla, atada con un cordel, había una roja bolsa de goma, de las que se llenan de agua caliente, que parecía llena, y sobre la bolsa ise paseaba un caracol! La presencia de este surtido parecía extraña e inexplicable en el patio de la casa de Freud. (Dalí, 1981, p. 27).

Dalí le presenta a Freud un escrito de su autoría sobre el método "paranoico-crítico", que era un método de inducción y aprovechamiento de múltiples imágenes de persecución o megalomanía, idea influida por el pensamiento surrealista, en el cual se creía en la importancia que tenía el inconsciente en el arte y la poesía, cuyo objetivo era que el artista plasmara las asociaciones visuales emitidas de la profundidad de su personalidad $^{1}$. Durante su visita, Dalí realizó un retrato de Freud. En esta imagen el pintor presenta al psicoanalista con una expresión de disgusto en su rostro, por lo que los comentadores sugieren que los trazos de la obra ilustran el sentimiento generado por el rechazo de Freud, proyectando así los sentimientos de rabia de Dalí en el retrato de un Freud moribundo. Dalí (1981) describe el encuentro y su apreciación de este en la siguiente narración:

Contrariamente a mis esperanzas, hablamos poco, pero nos devorábamos mutuamente con la vista. Freud sabía poco de mí, fuera de mi pintura, que admiraba, pero de pronto sentí el antojo de aparecer a sus ojos como una especie de dandy del "intelectualismo universal". Supe más adelante que el efecto producido fue exactamente lo contrario
[...]. Antes de partir quería darle una revista donde figuraba un artículo mío sobre la paranoia. Abrí, pues, la revista, en la página de mi texto, y le rogué que lo leyera si tenía tiempo para ello. Freud continuó mirándome fijamente sin prestar la menor atención a mi revista. Tratando de interesarle, expliquele que no se trataba de una diversión surrealista, sino que era realmente un artículo ambiciosamente científico y repetí el título, señalando al mismo tiempo con el dedo. Ante su imperturbable indiferencia, mi voz se hizo involuntariamente más aguda y más insistente. Entonces, sin dejar de mirarme con una fijeza en que parecía convergir su ser entero, Freud exclamó, dirigiéndose a Stefan Zweig: "nunca vi ejemplo más completo de español- iqué fanático!". (p. 27).

Dalí, que llevaba donde Freud todas sus posesiones preciadas para ser admiradas, recibió de parte de él una respuesta decepcionante. Freud hablaba con Zweig sobre Dalí, de manera tal que este último parecía no estar presente, pues Freud escasamente reconoció la presencia del pintor catalán (Room y Slap, 1983, p. 345).

Transcurridos cuatro meses desde el encuentro, Dalí se pregunta por el destino del retrato de Freud, y acudió así a Stefan Zweig, a quien había encomendado la tarea de enseñar el retrato al neurólogo austriaco, con el objetivo de conocer la apreciación de Freud (Motta, 2010), pero este le contesta con una actitud evasiva. En el retrato, como sugieren Romm y Slap, los ojos de Freud transmiten un sentimiento de frialdad y una expresión de ira en el rostro, lo que refleja la percepción que tenía Dalí de la actitud evasiva de él.

Salvador Dalí relata esta anécdota con algunas variaciones y hace explícita su intención al retratar a Sigmund Freud:

Al parecer, sin darme cuenta, dibujé la muerte terrestre de Freud en el retrato al carbón que hice de él un año antes de su muerte. Mi intención especial había sido realizar un dibujo puramente morfológico del genio del psicoanálisis, en lugar de intentar hacer de una forma evidente el retrato de un psicólogo. Terminado el retrato, rogué a Stefan Zweig, quien nos había presentado, que se lo enseñase, y después esperé con ansiedad los comentarios que pudiera formular. Me había alagado en extremo su exclamación en el momento en que nos encontramos: “¡Nunca había conocido a tan perfecto prototipo de español! ¡Qué fanático!".

Había dicho eso a Zweig después de observarme durante largo rato en modo terriblemente agudo. No obstante, no obtuve la respuesta de Freud hasta cuatro meses más tarde, cuando, acompañado de Gala, encontré de nuevo a Stefan Zweig y a su mujer en ocasión de una comida en Nueva York. Estaba tan impaciente que esperé el momento del café para preguntar cuál había sido la reacción de Freud en presencia de mi retrato. 
"Le ha gustado mucho" me dijo Zweig.

Insistí a pesar de todo, curioso por saber si Freud había hecho alguna observación concreta o el menor comentario que hubiera sido para mí infinitamente precioso, pero Stefan Zweig me pareció evasivo o distraído por otros pensamientos. Pretendía que Freud había apreciado mucho la "delicadeza de los rasgos”. (Dalí, 1981, p. 182).

Salvador Dalí destaca que la muerte de Freud fue "sin darse cuenta" retratada, es decir, fue predicha de manera inconsciente. Romm y Slap afirman que esta declaración parece suficientemente consciente; probablemente Dalí expresa su malestar hacia la indiferencia de Freud a través de su deseo de verlo muerto. De ser así, la utilización de la expresión "sin darme cuenta" es un indicador de que él pudo haber dirigido su sentimiento de culpabilidad como consecuencia de su deseo homicida.

El día posterior a dicho encuentro, Freud (1938) escribe una carta dirigida a Zweig en la que plasma sus opiniones de Dalí:

Realmente tengo razón para agradecerle por la introducción que me trajo el visitante de ayer. Porque hasta entonces me inclinaba a considerar a los surrealistas, quienes aparentemente me han elegido como su santo patrón, como absolutos (digamos 95 por ciento, como el alcohol) excéntricos. El joven español, sin embargo, con sus ojos cándidos fanáticos y su indiscutible dominio técnico, me ha hecho reconsiderar mi opinión. Sería en efecto muy interesante para investigar analíticamente cómo una imagen como esta llegó a ser pintada. Desde el punto de vista crítico aún podría sostenerse que la noción de arte desafía expansión, siempre y cuando la proporción cuantitativa de material inconsciente y tratamiento preconsciente no permanece dentro de los límites definidos. En cualquier caso se trata de graves problemas psicológicos. (pp. 448 449) ${ }^{1}$.

Como se puede apreciar en la correspondencia escrita por Freud, la visita de Salvador Dalí le produjo un cambio de opinión; dicha transformación de pensamiento es vista por Rose (1983) como un "contraste dramático y dinámico que sintió dentro de Dalí lo que lo interesó" (p. 353). Freud observó y reconoció la combinación entre pasión y control que Dalí encarnaba.

Dos meses después de su último encuentro con Stefan Zweig, se conoce del doble suicidio de él y de su esposa Charlotte Elisabeth Altmann en Petrópolis, Brasil, lugar donde huyeron por la situación de Europa y la persecución de los judíos. Ese último encuentro fue en Brasil, luego de que Dalí y Gala fueran invitados por los Zweig. Después de conocerse la noticia del suicidio, Dalí conoce la obra póstuma de Zweig titulada $E l$ mundo de mañana y en ella descubre otra versión de lo que sucedió con Freud y el retrato que le elaboró:

Únicamente al leer el libro póstumo de Stefan Zweig, Elmundo de mañana, supe al fin la verdad sobre mi dibujo: Freud

1 Traducción del autor.

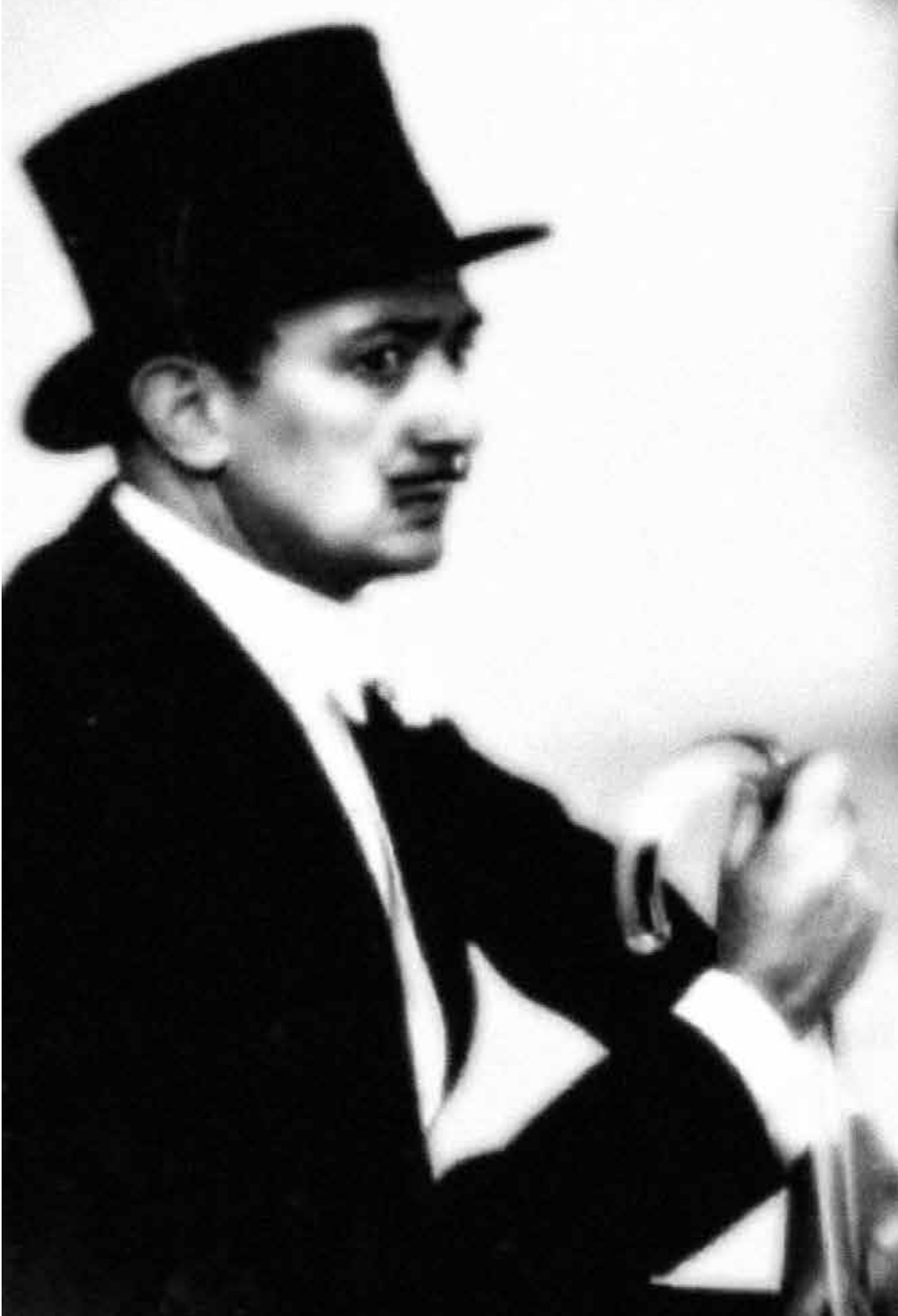


jamás vio su propio retrato. Zweig me había mentido piadosamente. Según él, mi retrato presagiaba de una manera tan clara la inminente muerte de Freud, que no se había atrevido a mostrárselo, temiendo sobresaltarle innecesariamente, sabiendo que era víctima de un cáncer. (Dalí, 1984, p. 184).

Un cuarto y último retrato de Sigmund Freud fue realizado por Dalí en 1938. Allí muestra a Freud, según Romm y Slap (1983), en una posición de escucha activa, propia de su actividad como psicoanalista, además con una mirada profunda e intensa.

\section{Surrealismo y psicoanálisis}

Según Maddox (1990), desde el primer manifiesto surrealista de André Bretón, el surrealismo implicó una nueva visión y utilización del inconsciente como fuente de inspiración, gracias al influjo de la obra psicoanalítica y la experiencia de Breton en el campo de la psiquiatría. Dicha corriente artística tenía sus bases teóricas en el estudio del automatismo psíquico, que busca expresar la acción real de pensar mediante diferentes canales, y se propone liberar la mente de las limitaciones de la razón y de cualquier cuidado moral o estético, con el fin de buscar las asociaciones de ideas, creyendo en que una realidad superior subyace a dichas asociaciones, profesando fervientemente la actividad magnánima del pensar y la facultad suprema de los sueños.

La fascinación de Breton por la obra de Freud se remonta a su juventud, periodo en el cual se desempeñó como ayudante en el centro psiquiátrico de la segunda división de Saint Dizier, mientras transcurría la Primera Guerra Mundial. Fue bajo la supervisión de un médico psiquiatra de apellido Leroy que Bretón conoció el texto La interpretación de los sueños y se fascinó con la obra freudiana (Esman, 2011). Por su parte, Ibáñez (2010) indica que el encuentro de Breton con la literatura psicoanalítica se dio después, pero su interés por la psiquiatría tomó forma en 1917, un año después de su ingreso al centro psiquiátrico militar luego de haber solicitado su traslado a dicha institución debido a sus deseos de continuar con su carrera médica, la cual había iniciado en 1913, pero que decidió suspender con el fin de enlistarse en el ejército.

En su labor como ayudante de psiquiatría en Saint Dizier, Breton se sumergió en la literatura psicológica y psiquiátrica de la época, en la que se destacan las obras de autores como Ballet, Gilbert, Jean Martin Charcot, Pascal, entre otros, a la vez que se enfrentaba a la experiencia con enfermos mentales y pacientes afectados por la guerra. Trabajó con el Dr. Babinski, quien había sido estudiante de neurología de Charcot. Según Ibáñez (2010), es después de la Primera Guerra Mundial que Breton se encuentra con la literatura psicoanalítica, gracias a la incursión de esta corriente de pensamiento en Francia. A través de los textos La interpretación de los sueños, Psicopatología de la vida cotidiana, "Recuerdo de la infancia de Leonardo" y "La Gradiva de Jensen", Breton estructura un método de creación el cual denomina "escritura automática" (Ibáñez, 2010, p. 78). Según Garland (2005), Dalí y sus primeros compañeros (Aragón, Vitrac, Soupault) "organizaban encuentros experimentales con el inconsciente, a través de sueños provocados, drogas o hipnosis; situaciones que los llevaban a un paso de la ruptura entre ellos mismos. Incluso del suicidio o la locura" (p. 60), lo que les permitía dar lugar a la fantasía, y generar el contexto ideal para el nacimiento de una nueva experiencia estética y literaria. Estas experiencias, nos indica Davis (1973), consistían en escribir rápidamente sin detenerse para hacer una segunda lectura o llevar a cabo corrección 


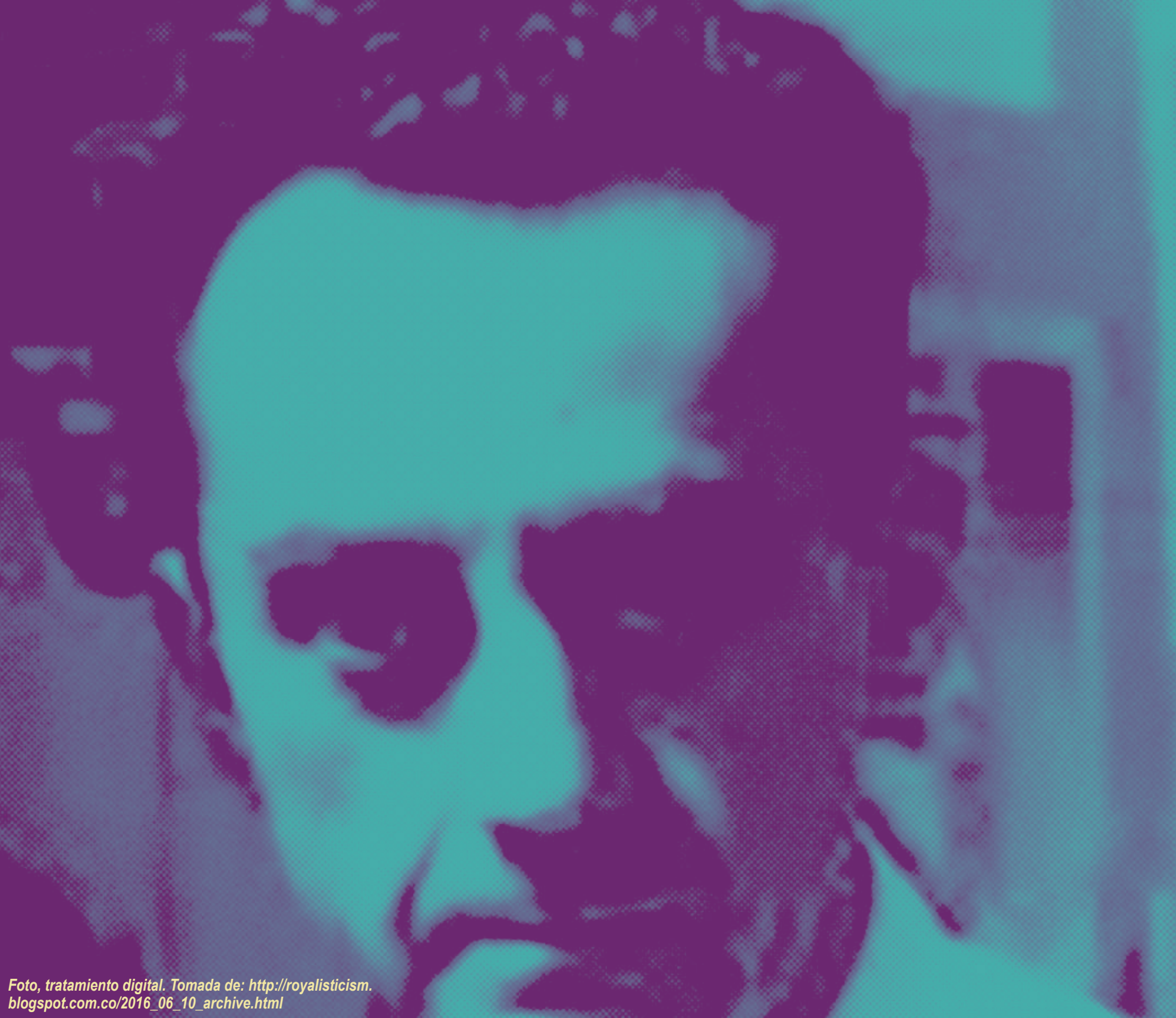

a particulares dotes, plasmando sus fantasías en un nuevo tipo de realidades efectivas que los hombres reconocen como unas copias valiosas de la realidad objetiva misma. Por esa vía se convierte, en cierto modo, realmente en el héroe, el rey, el creador, el mimado de la fortuna que querría ser, sin emprender para ello el enrome desvió que pasa por la alteración real del mundo exterior. Ahora bien, solo puede alcanzarlo porque los otros hombres sienten la misma insatisfacción que él con esa renuncia real exigida, porque esa insatisfacción que resulta de la sustitución del principio de placer por el principio de realidad constituye a su vez un fragmento de la realidad objetiva misma. (p. 229).

De esta manera, la pulsión se destaca por una capacidad de cambiar el fin sexual a partir de la sublimación, siendo éste transformado por uno más distante y cuyo valor social es superior.

Según lo referido por Esman (2011), Breton, impulsado por su interés en la obra de Freud, decide viajar a Viena en octubre de 1921 con el objetivo de entrevistarse con él. Freud, aunque "teniendo poco tiempo libre en esos días" (p. 174), envió una nota de invitación al hotel donde se alojaba Breton para que asistiera a su casa en Berggasse 19 a las tres de la tarde. El encuentro fue decepcionante para Breton. Su experiencia la plasmó en un pequeño artículo de su autoría, titulado "Entrevista con el profesor Freud" ("Interview du Professeur Freud", su título en francés), el cual describe al neurólogo austriaco como

Pequeño hombre viejo sin estilo, quien recibe a clientes en una lamentable oficina digna del vecindario $[\ldots]$ yo traté de hacerlo hablar lanzando nombres como Charcot y Babinski en la conversación, pero ya sea porque los recuerdos que estoy llamando son muy distantes (!!) o porque él mantiene una postura de reticencia cautelosa con los extraños, solo pude hacerlo hablar de generalidades"; posteriormente Breton desestimó su encuentro como "un sacrificio lamentable para el espíritu de Dada. (Esman, 2011, p. 174).

En 1924, Breton publica el primer manifiesto surrealista, en el cual fija el punto de partida del surrealismo y, según los aportes de Ibáñez, en su interpretación del historiador Bozal (2000), lo sitúa como fenómeno de vanguardia debido a que cumple tres requisitos: en primer lugar, está ligado a la aparición de la bohemia a lo largo del siglo xx; en segundo lugar, la reacción del movimiento no solo es contra el estilo anterior, sino contra la falsificación o mistificación de la realidad que 
establece dicho estilo; y, por último, es incomprendido en un inicio, para posteriormente ser asimilado y digerido por el público burgués que comprará las producciones de dicho movimiento. Breton se remonta a la obra de Sigmund Freud para destacar el valor del estado del sueño. Según lo planteado por Ibáñez, desde su perspectiva Freud permitió definir la forma en que el inconsciente afecta las fuerzas manifiestas; el fin del surrealismo es captar las fuerzas ocultas y someterlas a la razón, que es el mismo fin que tiene el psicoanálisis, a partir de su método de la asociación libre. Pero Breton no tenía interés en el contenido latente de los sueños, en su lugar, estaba interesado en su utilización para crear una nueva estética, transformándolos en una poesía imposible de categorizar. Del mismo modo, usó este material onírico para difundir la evolución de su filosofía del arte, expresada abiertamente en sus manifiestos surrealistas (Spector, 1989).

El movimiento surrealista hizo uso de los aspectos técnicos del psicoanálisis, pero no compartió sus fines terapéuticos. En su lugar, los jóvenes autores publicaron sus sueños con una compleja mezcla de intenciones literarias, personales y políticas, en referencia al estatus de poder de quien soñaba frente a su grupo, al igual que los ideales $\mathrm{y}$ valores que estaban llevando una reforma social y que condujeron a un acercamiento con el marxismo (Spector, 1989, p. 290). Si bien el movimiento surrealista no fue el primero en dar un uso literario al sueño, se destaca por haber sido la primera corriente artística de vanguardia en hacer del sueño un punto central en sus fines artísticos y políticos. De esta manera, según el relato de Garland (2005), el surrealismo y el psicoanálisis de formas diferentes llegan a un postulado similar, "el de haber puesto al descubierto las flaquezas de un sistema basado en la represión, de allí su propuesta: dar un mayor espacio a la sinceridad" (p. 61).

Teniendo en cuenta lo anterior, es posible observar que la relación entre el surrealismo y el psicoanálisis iba hasta lo más profundo de la corriente artística. Como indica Davis, Breton hizo uso de ideas de la corriente de pensamiento en el desarrollo de su concepto de "lirismo" en la poesía, haciendo referencia a la expresión libre del control consciente, igualmente conocido como composición espontánea.

Esta relación entre el psicoanálisis y el surrealismo iba más allá del plano académico. Siguiendo el relato de Davis, Breton (1932) dedica su texto Les Vases communicants (Los Vasos comunicantes) a Freud, texto que contiene aproximadamente cincuenta sueños recogidos por distintos artistas surrealistas y para el cual Breton le solicitó a Freud que hiciera una contribución. La reacción de Freud ante esta solicitud, la cual mostraba la acogida entusiasta del movimiento surrealista de las ideas psicoanalíticas, fue cortés pero escéptica; según indica Davis (1973) su respuesta fue: “Una mera colección de sueños sin la asociación de quien sueña, sin el conocimiento de las circunstancias en los que ellos ocurrieron, no me dice nada, y difícilmente puedo imaginar lo que puedan contarle a cualquiera" (p. 128). A pesar de la fría respuesta de Freud, Breton decidió seguir adelante con sus exploraciones del fenómeno inconsciente. Breton le envía una copia dedicada de su libro a Freud, lo que da inicio a un intercambio de cartas relatado a profundidad por Davis (1973). En esas cartas se observa cómo Freud se molesta por un comentario de Breton en el que le reprocha que en La interpretación de los sueños no cita a Volkelt. Freud se extiende explicando que esta omisión ha sido producida durante el proceso de la edición francesa (a cargo de Otto Rank), pero que sí figuraba en la primera edición en alemán. Esa correspondencia pone en evidencia que la relación que Breton mantenía con Freud era ambivalente e intensa y fue objeto de satisfacciones, pero también de amargura y recriminaciones.

\section{Dalí y el surrealismo}

Dalí compartía la admiración y el interés de los surrealistas por la obra de Freud, haciendo evidentes sus vínculos con la obra freudiana en su queja contra los hábitos, aduciendo que, según Garland (2005), "de tanto ver la realidad dejábamos de verla, situación que proponía cambiar, apelando a la irracionalidad" (p. 27). Al tener conocimiento de la técnica de asociación libre de Freud y al ser usada de una manera particular por el movimiento surrealista de Breton, Dalí solo aceptó su utilización si era para modificarla con su labor consciente. Al no hacer uso de esta técnica, Dalí se mantuvo un año apartado del movimiento surrealista.

En 1928, Dalí, en compañía de los críticos Gash y Montanya, decide participar en la redacción del "Manifiest Groc" ("Manifiesto Amarillo"), el cual expresaba un nuevo espíritu posmaquinista (en sintonía con la tecnología) y, según Garland (2005), “denunciaba la falta de juventud en los jóvenes, lo que quería decir el miedo frente a los cambios; su temor al ridículo, los personalismos e incluso la indocumentación de los críticos" (p. 28). Dalí tuvo que enfrentarse en repetidas ocasiones a la censura, ante la negativa por parte de dos galerías de Barcelona de exhibir su obra Diálogo en la playa, posteriormente conocida como Deseos insatiufechos. Incluso un curador le había sugerido realizar modificaciones a la obra; Dalí se negó a realizar cambio alguno, con lo cual se consolidó su fama como incendiario.

En mayo de 1928, Salvador Dalí hizo pública su adherencia al movimiento surrealista de André Breton. El mal ambiente que invadía el mundo artístico en Barcelona lo hizo trasladarse a París, aprovechando la oportunidad que le brindaba la producción del filme Un chien andalou, película en la que participó en la creación del guion en compañía de Luis Buñuel. El filme, según la visión de Garland, desarrolla la temática freudiana del Edipo, formulación desarrollada en La interpretación de los sueños, según la cual en el mito de Edipo, al igual que en otros mitos y leyendas, estaría representada la castración. Al hacerse suscrito al círculo surrealista, Garland (2005) indica que Dalí “pudo reflejar la necesidad de verse respaldado por un grupo" (p. 31) debido a que veía en el movimiento surrealista de Breton un deseo de cambiar el mundo por medio del uso de las teorías y métodos psicoanalíticos.

El encuentro entre Dalí y Breton se realizó en 1928, coincidiendo con el segundo viaje del pintor español a Francia. Dicha reunión se llevó a cabo gracias al artista Joan Miró, quien los presentó. Se destaca del encuentro que Dalí nunca se expresaría con admiración hacía el poeta francés. En el número del 30 de diciembre de 1929 de la revista La Revolution Surrealiste se da el reconocimiento oficial de Salvador Dalí y Luis Buñuel como miembros del movimiento surrealista. Dalí presenta su primer discurso como miembro oficial de la corriente artística en 1930, en el Ateneu de Barcelona, con una intervención titulada "La posición moral del surrealismo". Allí Dalí acentúa el valor de la paranoia por encima de la escritura automática de Breton. Frente al objeto surrealista, Dalí (1981) puntualiza:

Estaba decidido a llevar a cabo y transformar en realidad mi divisa del "objeto surrealista" "el objeto irracional, el objeto de función simbólica” que oponía a los sueños narrados, la escritura automática, etc., y para conseguirlo decidí crear la moda de los objetos surrealistas. El objeto surrealista es un objeto absolutamente inútil desde el punto de vista práctico y racional, creado únicamente con el fin de materializar de modo fetichista, con el máximo de realidad tangible, ideas y fantasías de carácter delirante. (p. 335).

La obra de Breton se diferencia de la de Dalí en la medida en que esta, según nos indica Ibáñez (2010), “otorga una gran importancia al proceso mismo de creación y no solo a la creación en sí, sino también al producto. Además, la escritura automática implicó una cierta pasividad por parte del artista, pero no una transformación de la realidad" (p. 138).

\section{Jacques Lacan y el método paranoico-crítico}

Jacques Lacan entra en conocimiento de las tesis de Dalí sobre la paranoia a partir de un artículo del pintor titulado "Lane pourri" ("El burro podrido") y publicado en la revista Le Surréalisme au Service de la Révolucion. Este escrito, donde Dalí anticipaba lo que 
formalizaría como el método paranoico-crítico, influyó en las propia teoría lacaniana de la paranoia, quien hizo evidente esta influencia en su tesis doctoral titulada De las psicosis paranoicas y de su relación con la personalidad (Lacan, 1987). A raíz del descubrimiento de este artículo, Lacan le pide una cita a Dalí y es la primera de muchas veces que se encontraron en sus vidas. Según Roudinesco (1994), Lacan “encontraba en la posición daliliana el instrumento que faltaba a la teorización de su experiencia clínica en materia de paranoia" (p. 58). Según el escrito de Dalí, "todo delirio es ya una interpretación de la realidad y toda paranoia una actividad creadora lógica" (Roudinesco, 1994, p. 58). A través del método paranoico-crítico, Dalí presenta su disposición para cuestionar y desprestigiar la realidad.

El 22 de marzo de 1930, Dalí publica su texto La femme visible, obra en cuyo interior se encuentran los escritos "Lâne Pourri" y "Le Grand Masturbateur", entre otros. En éstos, el pintor presenta las bases de su nueva propuesta en el marco del movimiento surrealista. Según Dalí, citado por Roudinesco (1994),

Fue por un proceso netamente paranoico [...] como fue posible obtener una imagen doble: es decir, la representación de un objeto que, sin la menor modificación figurativa o anatómica, sea al mismo tiempo la representación de otro objeto absolutamente diferente, despojada a su vez de toda clase de deformación o anormalidad que pueda delatar algún arreglo. (p. 57).

Dalí usó el método psicoanalítico para estructurar su propuesta paranoico-crítica como estrategia creativa, defendiendo la parte activa del método. Además, buscó con su propuesta la materialización de imágenes irracionales e inconscientes.

Frente a la utilización del método psicoanalítico en la estructuración de la propuesta paranoica-critica, Lázaro (2010) puntualiza:

Para ello necesitaba un método que el psicoanálisis le pondría en bandeja. Un método lo suficientemente ambiguo y oscuro como para que, a la vez de mostrarnos el camino, fuera capaz de ocultarlo con la misma intensidad. Un método en el que su creador pudiera ser actor y espectador a la vez, juez y parte. Un método que ordenase de tal forma las percepciones que hiciera imposible determinar si la irracionalidad de su creador era simulada o real.

Y si el método psicoanalítico le brindaba la posibilidad de bajar a los infiernos de su inconsciente, de sus obsesiones personales, de sus imágenes preconscientes, de sus recuerdos infantiles, de sus fantasmas familiares, de sus conflictos sexuales, de recorrer los caminos que relacionan las dos tópicas freudianas, de analizar los procesos del sueño, el chiste o la paranoia o de bajar al mundo oculto de la creación, plasmar sus imágenes y poder retornar a la realidad ¿por qué no utilizarlo para recrear un método propio "espectacular y especular de sí mismo" "de carácter paranoico y activo del pensamiento", "que sistematizara la confusión, y adoptara una contribución al descrédito total del mundo de la realidad", que tuviera "su origen en el inconsciente", "haciéndonos soñar por su especial autopudor en el viejo mecanismo metafísico con algo que de buena gana confundiríamos con la esencia misma de la naturaleza, que según Heráclito, ama ocultarse"? (pp. 100-101).

El primero de junio de 1933, Dalí publica su texto "Nuevas consideraciones generales sobre el mecanismo del fenómeno paranoico desde el punto de vista surrealista", que es el prólogo del escrito: "Interprétation paranoïaque-critique de l'engime obsedante 'LAngélus' de Millet" (Dalí, 1978). El texto es un análisis exhaustivo de los mecanismos internos de los fenómenos paranoicos, el cual plantea una metodología con base en el poder súbito de las asociaciones sistemáticas particulares de la paranoia (Serrat y Villegas, 2007).

Para Dalí, la paranoia tiene una función de organizar las cosas cuando hay confusión, pues estas se presentan sin un orden lógico. La realidad, en un primer momento, se presenta desordenada, pero después puede ser sistematizada por la propia paranoia. Esta puede crear un nuevo sentido, el cual interpreta de forma delirante los acontecimientos del mundo real, vinculando de este modo una serie de objetos diferentes entre sí. Esta nueva forma de interpretación mantiene un interés constante en ser reconocida o comunicable por el otro. En su método paranoico-crítico, Dalí incorpora una serie de conceptos freudianos, según la narración de Lázaro (2010):

Por encima de todo, conviene recordar que Dalí aprendió del método freudiano la crítica del significado por la que ningún término debe tomarse tal como se presenta, porque es posible que detrás de él haya otro hecho oculto, latente, y detrás de este un tercero, etc., hasta llegar a encontrar el último significado, que es, posiblemente, diferente de aquel, sobre el que los seres humanos tienen conciencia. (p. 103).

Dalí también utiliza el método de la asociación libre y la regla fundamental del psicoanálisis, la cual indica decir todo lo que se piensa, "desde las ideas más absurdas, a las que parecen más inútiles, pues todo lo que se expresa se halla en conexión, más o menos directa, con el punto de partida al cual se desea llegar: la realización de deseos inconscientes" (Lázaro, 2010, p. 104). El pensamiento paranoico se caracteriza por tener un funcionamiento con la capacidad de justificar la unión de elementos disyuntos y de producir una imagen partiendo de otra. Esta segunda imagen intenta hacerse valer en el mundo real; es una idea que capta el pensamiento y se esfuerza por lograr el reconocimiento. Así, en una sola imagen, el artista introduce a voluntad una serie de imágenes, articuladas materialmente, integradas en una sola composición visual, pero la construcción de estas tiene que ver directamente con la capacidad paranoica de quien observa la imagen, pues es el mecanismo paranoico el que permite que una imagen al mismo tiempo represente otra.

Como se puede apreciar, la propuesta de Salvador Dalí se diferencia del método de André Breton en la medida en que permite una relación entre el sujeto y el fenómeno paranoico, mientras que, por su parte, la propuesta de la escritura automática implicaba una exclusión del sujeto. Además, el sueño y el automatismo son estados pasivos, a los cuales se les excluye del mundo exterior, lugar donde deberían expandirse libremente. Por su parte, Salvador Dalí presenta su propuesta paranoica como una actividad sistematizada, la cual está dirigida a una intromisión inquietante en el mundo de los deseos de todas las personas. Esta actividad paranoica pretende generar una crisis de la realidad y poner el mecanismo paranoico al servicio de la creatividad.

\section{Conclusiones}

Como ha podido observarse a lo largo de este recorrido, la relación entre Salvador Dalí y Sigmund Freud se caracterizó por la influencia del psicoanálisis en la vida y obra del pintor español. Dalí encontró en $L$ a interpretación de los sueños una obra que influenció de forma significativa su concepción estética, como fundamento teórico y fuente de inspiración de su actividad creativa. Del mismo modo, su acercamiento con el movimiento surrealista de André Breton lo familiarizó con las técnicas psicoanalíticas, pues dicho movimiento utilizó las premisas de la asociación libre para realizar ejercicios creativos, producir textos nunca antes pensados y buscar ejercer una articulación de la realidad del sueño con la realidad de la vigilia. 


\section{Referencias}

Breton A. (1932). Les Vases comunicantes. París: Gallimard. Bozal, V. (2000). Historia del arte en España II. Madrid: Ediciones Istmo.

Dalí, S. (1978). El mito trágico del “Angelus" Je Millet. Barcelona: Tusquets, col. Cuadernos Marginales.

Dalí, S. (1981). La vida secreta de Salvador Dalí. Figueras, Gerona: Dasa.

Dalí, S. (1984). Diario de un genio. Barcelona, España: Tusquets.

Davis, F. (1973). Three letters from Sigmund Freud to André Breton. Journal of the American Psychoanalytic Association, 21, 127-134.

Esman, A. (2011). Psychoanalysis and surrealism: André Breton and Sigmund Freud. Journal of the American Psychoanalytic Association, 59, 173-181.

Freud, S. (2004 [1900]). La interpretación de los sueños. Buenos Aires: Amorrortu Editores.

La propuesta de Breton, desarrollada luego de su acercamiento al psicoanálisis, se conoce como escritura automática; su objetivo era la creación de una "surrealidad" a partir de la articulación del mundo de los sueños y la vigilia. Esto significa que la propuesta de la escritura automática buscaba la expresión libre del control consciente y, de esta manera, propendía por la expresión automática de las ideas que se le presentaran al autor, y buscaba liberar al sujeto de las represiones del mundo real, lo que permitía que la fantasía se integrara en la percepción de la realidad para generar así una nueva. Breton hizo de Freud el patrono de su movimiento y el principal teórico de sus premisas. Por su parte, Dalí promulgó la influencia de Freud en sus obras, habiendo proclamado que sus obras eran concebidas con principios freudianos y en repetidas ocasiones dedicaba su trabajo al analista austriaco. La relación entre el pintor español y el analista austriaco no fue muy estrecha, pero, a pesar de esto, la imagen de Freud sí representó una influencia importante en la vida personal y artística de Dalí. Fascinado por la obra psicoanalítica, Dalí incorporó contenidos teóricos propios de esta corriente de pensamiento en su ejercicio plástico, e intentó, por medio del uso de la técnica psicoanalítica, establecer una nueva forma de interpretar y modificar la realidad. Dalí incluso utilizó sus propias teorías sobre la paranoia para emplearlas como un método de creación que denominó "paranoicocrítico". Se concluye, por lo tanto, que el psicoanálisis influyó de manera significativa en la vida y obra del pintor español, no solo porque a partir de este se fundamentaron las premisas del movimiento surrealista, sino por el interés personal de Dalí por la obra de Freud, encontrando en esas páginas unas claves inéditas para acceder al mundo de lo irracional y lo oculto del psiquismo humano. 
Foto, tratamiento digital. Tomada de: $h$ ttp://www.lainformacion.com/arte-cultura-y-espectaculos/pintura/elsurrealismo-y-el-sueno-reune-en-el-thyssen-el-universo-onirico-de-nombres-como-breton-dali-tanguy-y-manray_Fp18wS5FxmWdYGWFqm4Lz4/

Miguel Gutiérrez-Peláez. Ph. D. en Psicología de la Universidad de Buenos Aires (UBA). Profesor del Programa de Psicología de la Universidad del Rosario, Escuela de Medicina y Ciencias de la Salud, GI Individuo, Familia y Sociedad, Centro de Estudios Psicosociales (Cepso), Bogotá, Colombia.

www.urosario.edu.co

miguel.gutierrez@urosario.edu.co

Sergio A. González-Beltrán. Psicólogo del Programa de Psicología de la Universidad del Rosario, Escuela de Medicina y Ciencias de la Salud, Bogotá, Colombia.

gonzalezb.sergio@urosario.edu.co

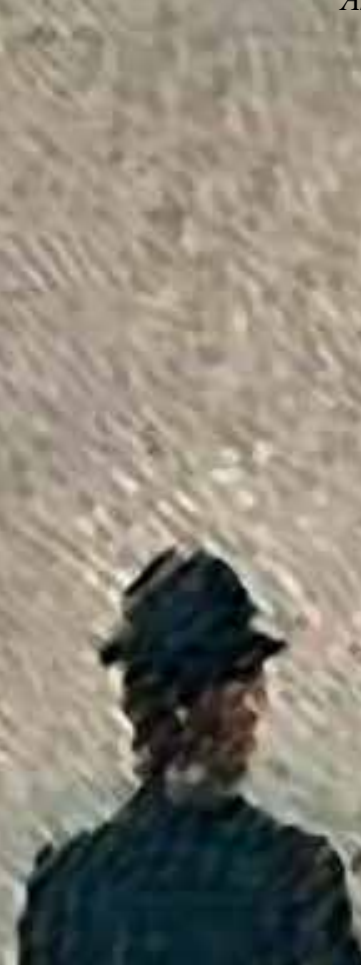

